\title{
First Responder ECHO: Developing an Innovative Telementoring Program
}

\author{
Neil Katzman', Jessica Medrano², Robin Swift'1, Paige Menking1 \\ ${ }^{1}$ ECHO Institute, University of New Mexico Health Sciences Center, Albuquerque, NM, USA \\ ${ }^{2}$ EMS, CEMS and CHW Programs, Central New Mexico Community College, Albuquerque, NM, USA \\ Email:katzman.neil@gmail.com
}

How to cite this paper: Katzman, N., Medrano, J., Swift, R., \& Menking, P. (2019). First Responder ECHO: Developing an Innovative Telementoring Program. Creative Education, 10, 1982-1987. https://doi.org/10.4236/ce.2019.109144

Received: August 13, 2019

Accepted: September 8, 2019

Published: September 11, 2019

Copyright (c) 2019 by author(s) and Scientific Research Publishing Inc. This work is licensed under the Creative Commons Attribution International License (CC BY 4.0).

http://creativecommons.org/licenses/by/4.0/

\begin{abstract}
First Responders across the globe suffer from increased rates of post-traumatic stress disorder (PTSD), depression, and compassion fatigue. Because their work environment places them on the front lines of crisis situations nearly every day, first responders experience a significant amount of trauma, which can lead to PTSD and other psychological symptoms. Project ECHO, a successful telementoring program, whose mission is to educate clinicians and other health care providers in rural and underserved communities, will be piloting a First Responder ECHO beginning September 2019. The primary goal of the First Responder ECHO is to improve the confidence and knowledge of First Responders in New Mexico. This First Responder ECHO will include an evaluation component. If the program is successful, the goal will be to expand to other regions of the United States.
\end{abstract}

\section{Keywords}

First Responder, Project ECHO, Telementoring, PTSD, Compassion Fatigue

\section{First Responder Background}

First responders include the firefighters, paramedics and police officers who serve on the front lines every day to protect our country (Benedek, Fullerton, Ursano, 2007). Whatever or wherever the need, our first responders keep America safe. Fire and rescue personnel remain a lifeline for many families across America. In rural towns and counties, they may be the only medical care in the region. Whether it is protecting the public's safety, using life-saving medications or cardiopulmonary resuscitation to save a life or transporting a patient to the closest hospital, first responders save countless lives every day (Faul et al., 2015). 
Over the last decade, there has been an increased recognition that first responders consistently experience increased rates of psychological distress, including depression, PTSD and compassion fatigue as compared to the general population (Brooks et al., 2016; Patterson et al., 2012; Smith et al., 2018; Jones et al., 2018). There have been nine known suicides of New York City police officers in 2019 (accessed August 24, https://www.nytimes.com/2019/08/13/nyregion/nypd-officer-suicide.html). The New York City Police Department is now adding mental health resources to most local precincts and offering counseling to all police officers regardless of rank and duty hours.

One example of increased stress for first responders is the growing opioid crisis. With approximately 130 Americans dying every day from opioids, first responders are called to 911 overdose emergencies at an alarming rate (Rudd et al., 2016). It is now common in many regions of the country for first responders to be deployed to the same call for an opioid overdose with naloxone more than two or three times in the same week (Faul et al., 2017). For first responders, this can lead to compassion fatigue and other psychological feelings of helplessness. For many first responders, it is not merely the act of providing the naloxone, the antidote to heroin or prescription opioids, which engenders a stress response. The multitude of other social triggers surrounding these situations can be even more traumatic, including witnessing traumatic conditions like severe filth, unsupervised or abused children, and a sense that there is no way to intervene with these social determinants of health (Bentley, Crawford, Wilkins, Fernandez, \& Sudnek, 2013; Milligan-Saville et al., 2018).

Although the rates of anxiety, PTSD, depression, compassion fatigue and substance use remain significant problems for first responders, there is hope that through education and understanding, these issues can be reduced if recognized early and processed adequately. A fundamental problem, however, is that many first responders often receive an unspoken message that they need to quickly "get over" their feelings to demonstrate strength and the ability to move on to the next call. It can be difficult to share traumatic experiences with loved ones at home, and while many first responder systems and organizations integrate ongoing debriefing and rapid availability of counseling services, the culture does not always encourage their utilization. Therefore, first responders may look for other ways to cope. Fortunately, there are now many known protective risk factors and interventions to help first responders to cope with their stressful work environments (Quevillon et al., 2016; Mitchell, 2011). These include: 1) reducing long working hours; 2) receiving gratitude; 3 ) and planning in advance of disasters.

Project ECHO has developed an innovative telementoring pilot for First Responders beginning weekly in September 2019. The goals of the First Responder ECHO are to increase the confidence, knowledge and joy of work for First Responders. Through this program, the authors hope to support partici- 
pating first responders in New Mexico with their psychological wellness and self-care. Project ECHO has been very successful throughout New Mexico by educating clinicians living in rural and underserved regions by: 1) demonstrating clinician practice change; 2) improved patient outcomes; 3 ) increased clinician satisfaction (Arora et al., 2011a). The authors believe that the telementoring platform will also benefit the First Responders throughout New Mexico (Table 1).

\section{Project ECHO}

Project ECHO (https://projectecho.org/) began in 2003 at the University of New Mexico Health Science Center as a mechanism to more effectively treat Hepatitis $\mathrm{C}$ in rural and urban underserved areas throughout New Mexico (Arora et al., 2011a). The ECHO model ${ }^{\mathrm{Tx}}$ uses telementoring to improve access to quality medical care, and paramedical care, education, and/or public health services and disseminate best practices to its target audience. The hallmark of the ECHO model is case-based learning, whereby the "spoke" clinician presents cases to the "hub" team and the entire network (both the hub and the spoke team together) collectively discuss and make treatment recommendations to the person presenting the case. Short didactics covering relevant and useful skills and knowledge are also presented at every tele ECHO program (Arora et al., 2011b). Zoom Videoconferencing technology is used to enable hub and spoke participants to see each other at all times.

Table 1. Proposed first responder curriculum.

Psychological Wellness:
1) Sources of anxiety and depression
2) Anger and fair fighting
3) Regulating anxiety
4) The role of a secure base
5) Modeling healthy behaviors
Opioids and Pain and the Complex Healthcare System:
6) Epidemiology of the opioid and pain crises
7) Responding to an overdose with Naloxone
8) Navigating a complex healthcare system
9) What is chronic pain
10) What is addiction/substance use disorder

\section{Taking Care of Yourself:}

11) Compassion fatigue

12) Identifying and reducing the risk of post-traumatic stress disorder

13) Importance of self care

14) How to communicate with your co-workers daily 
ECHO programs also provide no-cost continuing education credits to physicians, nurses, pharmacists, social workers and community health workers. Project ECHO is a proven and cost-efficient method for increasing the capacity of front-line health care professionals and educators to provide specialist-level treatment in their own communities. There are 70 different types of ECHO programs now available in all 50 states and in over 30 countries.

The ECHO Institute has extensive experience in operating behavioral health, pain and opioid ECHO programs in addition to programs related to improving the public health and social services of healthcare and service providers throughout the country. These tele-ECHO programs include: The Chronic Pain and Opioid Management ECHO, Behavioral Health and Addiction ECHO, Medication Assisted Training (MAT) ECHO, Community Health Worker (CHW) Opioid ECHO, and the Crisis Intervention ECHO, for law enforcement (Hager et al., 2018; Crisanti et al., 2019).

The proposed spoke participants for the First Responder ECHO are: emergency medical technicians (all levels of training), firefighters, law enforcement and any other first responders. The proposed hub team will include: an EMT instructor, firefighter, law enforcement, a Psychiatrist, a Pain Management Specialist, an Emergency Medicine Physician and a Peer Support Specialist/Community Health Worker (Figure 1).

\section{Evaluation}

As part of receiving no-cost continuing education credits, participants in the weekly First Responder ECHO will respond each week to a brief set of questions asking them if the program met their educational needs. The very brief survey includes five questions related to how the First Responder ECHO might have improved: 1) self-efficacy; 2) knowledge; 3) practice change; and 4) whether or not the participant is likely to return to the program.

\section{First Responder ECHO: Hub \& Spoke Network}

\begin{tabular}{|l|l|}
\hline - Firefighter \\
- Paramedic \\
- Police Officer \\
$\begin{array}{l}\text { Mediction / Pain } \\
\text { - Emergency Physician } \\
\text { - Community Health } \\
\text { Worker }\end{array}$
\end{tabular}

Figure 1. Project ECHO Hub and spoke model for the first responder ECHO. 
The authors plan to study both pre/post quantitative and qualitative components to generate the most robust study results as possible. Some of the quantitative measures will include: anxiety and depression scores, quality of life scales, and a common PTSD tool used for first responders. Other items to quantify are the number of sessions each first responder attended, their comments on the weekly continuing education questions, and participation during the session. Pre and post focus group sessions will also be performed virtually, using the Zoom video-conferencing technology-for the first responders. Focus group sessions will explore issues that cannot be easily identified through the quantitative measures. These will include: reasons for joining the weekly First Responder ECHO sessions, how the First Responder ECHO has changed behavior, thinking practice, etc.

\section{Conclusion}

It is our hope that the initiation of this project will serve as a resource to connect first responders to each other and to experts in the field in New Mexico and around the United States. The goals of this First Responder ECHO are to: provide: 1) continued learning of best practices; 2 ) provide a community of practice for first responders; 3 ) promote psychological wellness in this critical workforce. First responders perform such important work which serves all.

\section{Conflicts of Interest}

The authors declare no conflicts of interest regarding the publication of this paper.

\section{References}

Arora, S., Kalishman, S., Dion, D., Som, D., Dion, D., Thornton, K., Bankhurst, A., Boyle, J., Harkins, M., Moseley, K., Murata, G., Komaromy, M., Katzman, J., Colleran, D. P., \& Yutzy, S. (2011a). Partnering Urban Academic Medical Centers and Rural Primary Care Clinicians to Provide Complex Chronic Disease Care. Health Affairs, 30, 1176-1184. https://doi.org/10.1377/hlthaff.2011.0278

Arora, S., Thornton, K., Murata, G., Deming, P., Kalishman, S., Dion, D., Parish, B., Burke, T., Pak, W., Dunkelberg, J., Kistin, M., Brown, J., Jenkusky, J., Komaromy, M. \& Qualls, C. (2011b). Outcome of Treatment for Hepatitis C Virus Infection by Primary Care Providers. The New England Journal of Medicine, 364, 2199-2207. https://doi.org/10.1056/NEJMoa1009370

Benedek, D. M., Fullerton, C., \& Ursano, R. J. (2007). First Responders: Mental Health Consequences of Natural and Human Made Disasters for Public Health and Public Safety Workers. Annual Review of Public Health, 28, 55-68. https://doi.org/10.1146/annurev.publhealth.28.021406.144037

Bentley, M. S., Crawford, J. M., Wilkins, J. R., Fernandez, \& Sudnek, J. R. (2013). An Assessment of Depression, Anxiety and Stress among Nationally Certified EMS Professionals. Prehospital Emergency Care, 17, 330-338. https://doi.org/10.3109/10903127.2012.761307

Brooks, S. K., Dunn, R., Amlot, R., Greenberg, N., \& Rubin, G. J. (2016). Social and Occupational Factors Associated with Psychogical Distress and Disorder among Disaster 
Responders: A Systemic Review. BMC Psychology, 4, 18. https://doi.org/10.1186/s40359-016-0120-9

Crisanti, A. S., Earheart, J. A., Rosenbaum, N. A., Tinney, M., \& Duhigg, D. J. (2019). Beyond Crisis Intervention Team (CIT) Classroom Training: Videoconference Education for Law Enforcement. International Journal of Law and Psychiatry, 62, 104-110. https://doi.org/10.1016/j.ijlp.2018.12.003

Faul, M., Dailey, M. W., Sugarman, D. E., Sasser, S. M., Levy, B., \& Paulozzi, L. J. (2015). Disparity in Naloxone Administration by Emergency Medical Service Providers and the Burden of Drug Overdoses in US Rural Communities. American Journal of Public Health, 105, e26-e32. https://doi.org/10.2105/AJPH.2014.302520

Faul, M., Lurie, P., Kinsman, J. M., Dailey, M. W., \& Crabaugh, S. M. (2017). Multiple Naloxone Administrations among Emergency Medical Service Providers Is Increasing. Prehospital Emergency Care, 21, 411-419. https://doi.org/10.1080/10903127.2017.1315203

Hager, B., Hasselberg, M., Arzubi, E., Betlinski, J., Duncan, M., Richman, J., \& Raney, L. E. (2018). Leveraging Behavioral Health Expertise: Practices and Potential of the Project ECHO Approach to Virtually Integrating Care in Underserved Areas. Psychiatric Services, 69, 366-369. https://doi.org/10.1176/appi.ps.201700211

https://www.nytimes.com/2019/08/13/nyregion/nypd-officer-suicide.html

Jones, S., Nagel, C., McSweeney, J., \& Curran, G. (2018). Prevalence and Correlates of Psychiatric Symptoms among First Responders in a Southern State. Archives of Psychiatric Nursing, 32, 828-835. https://doi.org/10.1016/j.apnu.2018.06.007

Milligan-Saville, J., Choi, I., Deady, M., Scott, P., Tan, P., Calvo, R., Bryant, R. A., Glozier, N., \& Harvey, S. B. (2018). The Impact of Trauma Exposure on the Development of PTSD and Psychological Distress in a Volunteer Fire Service. Psychiatry Research, 270, 1110-1115. https://doi.org/10.1016/j.psychres.2018.06.058

Mitchell, J. T. (2011). Collateral Damage in Disaster Workers. International Journal of Emergency Mental Health and Human Resilience, 13, 121-125. https://www.ncbi.nlm.nih.gov/pubmed/21957725

Patterson, P. D., Weaver, M. D., Frank, R. C., Warner, C. W., Martin-Gill, C. G. et al. (2012). Association between Poor Sleep, Fatigue, and Safety Outcomes in Emergency Medical Services Providers. Prehospital Emergency Care, 16, 86-97. https://doi.org/10.3109/10903127.2011.616261

Quevillon, R. P., Gray, Erickson, S. E., Gonzalez, E. D., \& Jacobs, G. A. (2016). Helping the Helpers: Assisting Staff and Volunteers Workers before, during and after Disaster Relief Operations. Journal of Clinical Psychology, 72, 1348-1363.

https://doi.org/10.1002/jclp.22336

Rudd, R. A. et al. (2016). Increases in Drug and Opioid-Involved Overdose DeathsUnited States, 2010-2015. Weekly, 65, 1445-1452.

https://doi.org/10.15585/mmwr.mm655051e1 https://www.cdc/mmwr/volumes/65/mm65051e1.htm

Smith, L. J., Gallagher, M. W., Tran, J. K., \& Vujanovic, A. A. (2018). Postraumatic Stress, Alcohol Use, and Alcohol Reasons in Firefighters: The Role of Sleep Disturbance. Comprehensive Psychiatry, 87, 64-71. https://doi.org/10.1016/j.comppsych.2018.09.001 